\title{
A construção da educação mundial ou o lugar da Educação Comparada no estudo das políticas (e práticas) de educação ${ }^{1}$
}

Palestrante: António Neves Duarte Teodoro.

A escola e a escrita, sem ser necessário estabelecer laços implicativos absolutos, são duas invenções humanas que procedem de condições similares. Ao consagrar a superioridade da escrita sobre a cultura oral, do trabalho intelectual sobre o trabalho manual, do espírito sobre a mão, o sistema escolar obteve uma das suas maiores vitórias, tornando-se um dos lugares centrais no processo de construção da modernidade.

A relação entre a afirmação da escola e da escrita e a construção da modernidade tem sido equacionada por diversos autores - por exemplo, Petitat (1984). A propósito da história da alfabetização, Justino Magalhães (1994) interrogou a ligação entre alfabetização e desenvolvimento histórico, ou, dito de outro modo, se a transição da oralidade à escrita se traduziu numa alteração profunda do pensamento humano. Como resposta, o autor avança a hipótese de que a alfabetização, não sendo suficiente para despoletar movimentos globais de mudança, surge como um meio facilitador. Se entre o oral e o escrito podem existir zonas de dicotomia e de ruptura, há sobretudo uma interação e passagens sucessivas, o que conduziu a que a escrita reduzisse a capacidade de representação da palavra, substituísse a memória e permitisse uma distanciação entre sujeito e objecto; ou seja, a escrita apela à intelectualização, a oralidade ao sensorial.

Apesar de fazer uma leitura crítica do "mito da literacia", Justino Magalhães (1994), suporta a posição de que o principal contributo da alfabetização para o desenvolvimento histórico foi o de criar uma predisposição para a mudança e para a mobilidade em sentido genérico.

1 Palestra proferida no painel Educação comparada e internacional: enfoques e limites do Seminário Internacional Repesensando a universidade comparativamente entre países: Brasil, Rússia, İndia e China, realizado pela Capes em parceria com o Instituto Lemann, da Universidade de Standford, e a UNESCO em 9 de dezembro de 2015. 
A instituição escolar foi a grande responsável pela difusão da escrita. Apesar de múltiplas dificuldades práticas e de diferentes ritmos de expansão, a escola assumiu-se desde cedo como um fenómeno global, que, na perspectiva neoinstitucionalista, se desenvolveu por "isomorfismo" no mundo moderno (ver, por exemplo, Meyer e Ramirez, 2000). Como todos os fenómenos globais, a escola dos nossos dias tem uma raiz local, tratando-se de um modelo construído no contexto europeu, só depois, progressivamente, universalizado à medida que se foi procedendo à integração dos diferentes espaços na economia mundo capitalista.

A consolidação do modelo escolar entre os séculos XVI e XVIII, em detrimento dos modos antigos de aprendizagem, é fruto de um longo processo, produzido no seio de um jogo complexo de relações sociais e de modificações das representações e das orientações normativas respeitantes ao mundo e aos homens, como aponta António Nóvoa (1994), compreensível num quadro onde, em paralelo, emerge (i) o desenvolvimento de uma nova concepção de infância, instaura-se (ii) uma civilização dos costumes, que impõe um ideal de adulto civilizado em contraponto à condição natural da criança, estabelece-se (iii) uma ética protestante do trabalho, e implanta-se (iv) uma sociedade disciplinar que tem como consequência o encerramento das crianças em espaços próprios.

É sob a sombra tutelar da Igreja que o modelo escolar se aperfeiçoa nesses três séculos fortemente influenciados pela Reforma e pela Contra-Reforma. Mas o século XVIII, ou o Século das Luzes, com as suas profundas transformações económicas, sociais e políticas, exige rupturas importantes no campo educativo e na organização da vida sociali. Em muitos países, o Estado toma o lugar da Igreja no controlo da educação, por meio de processos nem sempre pacíficos, e vai-se tornar o mais importante agente de expansão da instituição escolar.

Ao longo de todo o século XIX, a escola é transformada num elemento central de homogeneização linguística e cultural, de invenção da cidadania nacional, em suma, de afirmação do Estado-Nação. Como não se cansam de sublinhar os autores que perfilham a perspectiva 
do sistema mundial moderno, a expansão da escola encontra-se intimamente ligada à construção dessa realidade imprescindivel ao novo estádio da economia mundo capitalista, o Estado-Nação.

A progressiva expansão da escola a todas as camadas e grupos sociais conduziu à consolidação de modelos de organização escolar e de organização pedagógica capazes de abranger um cada vez maior número de alunos. Com esse propósito, desde o século XIX que se tem vindo a desenvolver uma gramática da escola², capaz de dar resposta ao desafio de ensinar a muitos como se fosse a um só (BARROSO, 1995).

O modelo de escola desenvolvido inicialmente na Europa vai tornar-se não apenas universal, mas também quase o único possivel ou mesmo imagináve/ (NÓVOA, 1998). A análise de como esse modelo de escola se afirmou e consolidou nos diferentes espaços mundiais tem constituído o campo de estudo privilegiado da Educação Comparada. Sendo uma disciplina das Ciências da Educação que pode remontar ao início do século XIXii, foi todavia após a Segunda Guerra Mundial que a Educação Comparada teve um grande desenvolvimento e uma significativa expressão no conjunto das Ciências da Educação.

A criação de um vasto sistema de organizações internacionais de natureza intergovernamental, tanto no plano das Nações Unidas para além da própria ONU, foram criadas organizações especializadas como a Unesco, nos campos da educação, ciência e cultura, ou no campo financeiro e da ajuda ao desenvolvimento, como o FMI e o Banco Mundial, ou no plano da cooperação económica num determinado espaço geográfico, como a OCDE, deu um forte impulso à internacionalização das problemáticas educacionais 3 .

A formulação das políticas educativas, particularmente nos países da periferia (e da semiperiferia) do sistema mundial, começou a depender, cada vez mais, da legitimação e da assistência técnica das organizações internacionais, o que permitiu, nos anos 60, uma rápida difusão das teorias do capital humano e da planificação educacional, núcleo duro das teorias da modernização, tão em voga nesse período de euforia, onde a educação se tornou um instrumento obrigatório

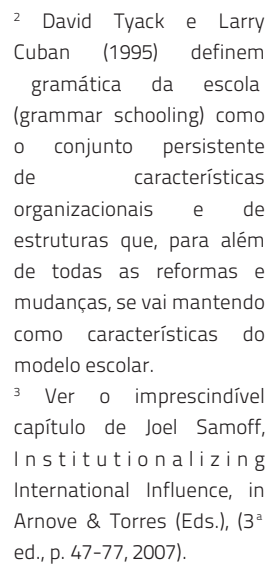


da autorrealização individual, do progresso social e da prosperidade económica (Husen, 1979). O esforço para estabelecer uma racionalidade científica que permitisse formular leis gerais capazes de guiar, em cada país, a ação reformadora no campo da educação esteve no centro das inúmeras iniciativas - seminários, congressos, workshops, estudos, exames - realizadas por todas essas organizações internacionais, permitindo criar vastas redes de contactos, de financiamentos e de permuta de informação e conhecimento entre autoridades político-administrativas de âmbito nacional, atores sociais, experts e investigadores universitários.

O desenvolvimento dessas redes assentou numa concepção de Educação Comparada centrada, segundo António Nóvoa (1998, p. 62-65), em torno de quatro aspectos essenciais: a ideologia do progresso, um conceito de ciência, a ideia do Estado-Nação e a definição do método comparativo. O primeiro aspecto, a ideologia do progresso, manifestase na equação educação = desenvolvimento, ou seja, na convicção de que a expansão e a melhoria dos sistemas educativos asseguram inelutavelmente o desenvolvimento socioeconómico. O segundo aspecto, um conceito de ciência, assenta no paradigma positivista das ciências sociais construídas a partir da segunda metade do século XIX, que atribui à ciência - neste caso, à Educação Comparada - o papel de estabelecer leis gerais sobre o funcionamento dos sistemas educativos, legitimando a retórica da racionalização do ensino e da eficácia das políticas educativas, apontada como o cerne de toda a ação reformadora. O terceiro aspecto, a ideia do Estado-Nação, decorre da assunção de nação como a comunidade privilegiada de análise, o que conduz, em geral, a estudos em que se procura sublinhar, sobretudo, as diferenças e as similitudes entre dois ou mais países. O quarto e último aspecto, a definição do método comparativo, tem na retórica da objectividade e da quantificação a sua dimensão principal, o que põe o problema da recolha e da análise dos dados e raramente (ou nunca) essa outra questão, mais decisiva, que é a própria construção dos dados e dos enquadramentos teóricos que lhes subjazem.

Talvez por essas suas origens, a Educação Comparada, no seu paradigma vulgarizado pela generalidade das organizações 
internacionais, produziu um conhecimento muito limitado, servindo antes, sobretudo, para as autoridades nacionais legitimarem as suas políticas. Prevalece aí um positivismo instrumental, que conduz ao que Thomas Popkewitz e Miguel A. Pereyra (1994) designam de falácias epistemológicas da investigação comparativa.

Nessa perspectiva, o recurso ao estrangeiro funcionou (e funciona), em geral, como um elemento de legitimação de opções assumidas no plano nacional, e muito pouco como um esforço sério de um conhecimento contextualizado de outras experiências e de outras realidades. Dito de outro modo, não tão radical, esta relação reflete sempre "uma aliança tácita, ou explícita, entre (algumas) forças internas e (algumas) forças externas"."

Mas, simetricamente, pode-se também considerar que as constantes iniciativas, os estudos e as publicações das organizações internacionais desempenham decisivo papel na normalização das políticas educativas nacionais, estabelecendo uma agenda que fixa não apenas prioridades mas igualmente as formas como os problemas se colocam e equacionam, e que constituem uma forma de fixação de um mandato, mais ou menos explícito conforme a centralidade dos países. Jurgen Schriewer (1997) designa essa forma de mandato, difuso mas presente, de "construção semântica da sociedade mundial”.

Possivelmente, esse carácter híbrido, entre a justificação de uma atividade reformadora ligada fundamentalmente à exportação do conceito de desenvolvimento e um método comparativo preso às formulações positivistas, trouxe à Educação Comparada uma "má reputação" (NÓVOA, 2005), particularmente nos anos 1970 e na primeira metade da década de 1980. Essa vieille damme compassée ("velha senhora sufocada”), na expressão de Regina Sirota (2001), vai dar lugar a uma nova "popularidade" da Educação Comparada, que, na opinião de António Nóvoa, assenta em três razões principais: a reorganização do espaço mundial, a recomposição dos sistemas educativos e a reestruturação do trabalho científico (NÓVOA; YARIV-MASHAL, 2005).

Não sendo este o local próprio para desenvolver a terceira razão apontada por Nóvoa (a reestruturação do trabalho científico),

\footnotetext{
Esta formulação é de Joel Samoff e foi apresentada numa reunião-debate com o autor deste programa, no âmbito de um convite dirigido pela Rede Iberoamericana de Investigação em Políticas de Educação (RIAIPE), na cidade do México, em 22 de novembro de 2007.
} 
centrar-me-ei então nas duas primeiras razões (a reorganização do espaço mundial e a recomposição dos sistemas educativos), procurando apresentar, em seguida, os argumentos que tenho vindo a elaborar sobre os modos como, nestes tempos de globalização (hegemonicamente neoliberal), os grandes inquéritos estatísticos (surveys) conduzidos por organizações transnacionais de natureza governamental, com destaque para a OCDE, têm vindo a se transformar no mais poderoso instrumento de regulação das políticas públicas de educação. E, a partir desses argumentos, tenho defendido que essa forma de "governar por números" torna empobrecedor o debate público democrático e obscurece outros modos de regulação, mais propícios a apoiar a inovação das respostas educativas, condição para a construção de uma escola exigente e radicalmente democrática.

O novo projeto de desenvolvimento gerado pela globalização hegemónica trouxe, para primeiro plano, uma estratégia de liberalização dos mercados mundiais, levando o axioma das vantagens competitivas a tornar-se o centro desse projeto e, desse modo, à recuperação da teoria neoclássica do capital humano. Não admira, então, que se argumente que os mais claros efeitos da globalização nas políticas educativas sejam consequência da reorganização dos Estados para se tornarem mais competitivos, nomeadamente de forma a atraírem os investimentos das corporações transnacionais para os seus territórios.

No anterior projeto desenvolvimentista, as relações entre os planos nacional e internacional na definição das políticas educativas nacionais processava-se num duplo registo: por um lado, a assistência técnica das organizações internacionais era (e é) ativamente procurada pelas autoridades nacionais, sobretudo como meio de legitimação das opções internas entretanto assumidas; por outro, as constantes iniciativas (seminários, conferências, workshops), estudos e publicações das organizações internacionais desempenham decisivo papel de normalização das políticas educativas nacionais, estabelecendo uma agenda que fixa não apenas prioridades, mas, igualmente, as formas como os problemas se colocam e se equacionam, e que constituem uma forma de fixação de mandato, mais ou menos explícito conforme a centralidade dos países ${ }^{5}$. 
No projeto da globalização - e essa é a hipótese que tenho vindo a defender desde 2001 (TEODORO, 2001, 2003a, 2003b, 2007, 2011) -, essas relações estabelecem-se sobretudo tendo como centro nevrálgico os grandes projetos estatísticos internacionais e, muito em particular, o projeto Indicators of Educational Systems (INES), do Centre for Educational Research and Innovation (CERI), da OCDE. Nesses projetos estatísticos, a escolha dos indicadores constitui a questão determinante na fixação de uma agenda global para a educação ${ }^{6}$, com um enorme impacto nas políticas de educação dos países centrais, mas igualmente dos países situados na semiperiferia dos espaços centrais.

O projeto INES foi marcado, de início, por uma forte controvérsia e uma larga oposição interna no seio da OCDE (HENRY et al. 2001) iii. Tendo como expressão pública mais conhecida a publicação anual de Education at a Glance, este empreendimento da OCDE foi decidido na sequência de uma conferência realizada em Washington, em 1987, por iniciativa e a convite do Governo dos Estados Unidos e do Secretariado da OCDE, em que participaram representantes de 22 países, bem como diversos peritos e observadores convidadosiv. 0 ponto principal da agenda da OCDE no campo da educação era, nessa época, a qualidade do ensino, que serviu como questão de partida para o lançamento do projeto INES, possivelmente a mais significativa e importante atividade dessa organização internacional em toda a década de 1990.

Reconhecendo que o problema mais complexo não era tanto o cálculo de indicadores válidos, mas a classificação dos conceitos, os representantes dos países-membros da OCDE e os peritos convidados examinaram um conjunto de mais de 50 indicadores nacionais possíveis, tendo acabado por reuni-los em quatro categorias: (i) os indicadores de input (entrada), (ii) os indicadores de output (resultados), (iii) os indicadores de processo, e (iv) os indicadores de recursos humanos e financeiros (BOTTANI; WALBERG, 1992).

A concretização desse projeto permitiu à OCDE estabelecer uma importante base de dados de indicadores nacionais de ensino, que alimenta a publicação, desde 1992, do Education at a Glance. Nesses olhares, para além dos tradicionais indicadores, sejam as diferentes taxas
${ }^{5}$ Para o caso de Portugal, e para o período compreendido entre 0 final da Segunda Guerra Mundial e a adesão, em 1986, à então Comunidade Económica Europeia (CEE), ver Teodoro (2001b).

${ }^{6}$ Como explicitarei adiante, a influência desses grandes projetos estatísticos vai bem mais além da mera fixação da "agenda global da educação". 
de escolarização, os vários índices de acesso à educação, as despesas com a educação, as qualificações do pessoal docente, figura um conjunto de novos indicadores que têm profundas consequências, "a montante", na formulação das políticas de educação no plano nacional’. Os mais importantes decorrem da definição do conceito de literacia ("letramento" no Brasil) e da escolha da língua materna, da matemática e das ciências como áreas de operacionalização desse conceito.

Os efeitos práticos desse projeto estão bem presentes nas políticas educativas adoptadas nos diferentes Estados-membros (ou associados) da OCDE desde a década de 1990, em geral pertencendo a espaços centrais ou na semiperiferia desses espaços centrais. Uma influência que se manifesta não por um mandato explícitov, mas pela necessidade de responder a uma agenda global baseada na comparação e, sobretudo, na competição de performances dos sistemas educativos. Como afirma Andy Green (2002), a obsessão com a medida dos resultados e das performances torna os governos (e, acrescento, demais atores políticos, com destaque para aqueles que possuem um acesso privilegiado aos meios de comunicação social de massas) prisioneiros de uma espécie de Jogos Olímpicos de nações, onde se colocam sob a forma de ranking os sistemas educativos em termos da sua eficácia.

São conhecidos múltiplos trabalhos que mostram os limites e a fragilidade dos fundamentos técnicos e científicos, bem como os problemas epistemológicos, das comparações internacionais de resultados (ver, por exemplo, Afonso e St. Aubyn, 2006; Bautier et al., 2006; Broadfoot et al., 2000; Normand, 2003, 2004). Um dos mais ilustres comparatistas mundiais, Martin Carnoy, presente no seminário, publicou em outubro de 2015, na Universidade de Stanford, um interessante relatório, International Test Score Comparisons and Educational Policy. A review of critiques (CARNOY, 2015), em que apresenta, de forma sistemática, o conjunto de críticas a esse modo de governar, com particular destaque para as apresentadas no contexto norte-americano.

7 Ver, por exemplo, os dois campos privilegiados pela OCDE nos finais da década de 1990: a avaliação do funcionamento das escolas e a avaliação externa das aprendizagens.
Mas a questão central está no fato de esse tipo de comparação se tornar uma arma muito poderosa para quem controla os "significados" do que é comparado. Isso mesmo é reconhecido por um antigo administrador principal do CERI-OCDE: 
Os estudos comparados funcionam como alavancas que permitem fazer saltar as resistências, não importa a que nível se situem, seja ao nível da investigação ou ao nível político. A comparação torna-se uma arma no conflito sobre a organização do ensino. Permite sobretudo implementar estratégias de informação novas sobre os processos educativos e trazer informações que aguçam e enfraquecem as posições dos adversários (BOTTANI, 2001, p. 75). ${ }^{8}$

Como sublinha Romuald Normand (2003), a obsessão pelos resultados e pela comparação internacional de performances se assenta no duplo propósito de, por um lado, "moldar" um modelo político para a educação e, por outro, institucionalizar um modo de governação que tende a confiscar o debate democrático e a impedir uma reflexão sobre o projeto político da escola.

Neste contexto, o poder das organizações internacionais nos tempos atuais vai além do já importante papel de fixação da agenda global da educação. Recorrendo a uma analogia com a distinção que Basil Bernstein faz entre recognição (“recognition”) e realização ("realisation")vi, Roger Dale (2008) defende que a influência das organizações internacionais - de entre as quais destaco a OCDE por considerar que constitui, pelo menos no campo da educação, o principal think tank mundial da globalização hegemónicavii - se situa não apenas na segunda dimensão de poder de Steven Lukes - "poder como definição de agenda" - mas também, sobretudo, na sua terceira dimensão - "poder de moldar e controlar as regras do jogo e de formatar as preferências" (p. 3) $)^{9}$. Por isso também a convicção de Roger Dale de que o papel das orgnizações internacionais tem vindo a mudar, assumindo-se cada vez mais como definidoras de problemas ("problem definers") e menos como provedores de soluções ("solution providers").

Os grandes inquéritos internacionais como o TIMSSviii, o PISA', o PIRLS ou o novel TALISxi (e, em alguns países, replicados no plano nacional), e a sua permanente comparação em relatórios e estudos internacionais (e nacionais), pouco (ou nada) preocupados com os contextos sócio-históricos geradores desses resultados, tornaramse uma das principais tecnologias de governação. O seu papel é o de fornecer as evidências para a ação política governativa (evidence-based

\footnotetext{
Sublinhe-se que, na casião em que a afirmação foi escrita, N. Bottani ainda desempenhava as funções de administrador principal do CERI-OCDE.

Dale refere-se ao livro de Steven Lukes, Power, a Radical View (London, Macmillan, 1. ed. $1974 ; 2$. ed., 2005).
} 
policy), remetendo para segundo plano a contextualização dos processos de aprendizagem, bem como a participação e o debate democráticos sobre as dimensões políticas da educação.

Este é o paraíso da governação neoliberal: uma ação política baseada em evidências apontadas pela expertise dos técnicos e cientistas, em vez da participação dos movimentos sociais e da sociedade civil organizada, associada à livre e democrática afirmação e concorrência de projetos políticos contrastantes. É, em suma, o velho sonho conservador de "fazer políticas sem política”, de um governo de "sábios" que conhece os caminhos e as soluções para tornar o "povo" felizxii.

\section{A concluir, uma proposta e um desafio}

Nos últimos anos a Fundação Capes tem vindo a demonstrar uma interessante (e inusitada) preocupação com a Educação Comparada, permitindo a tradução e difusão junto da comunidade de língua portuguesa de importantes obras desse campo científico. Refiro-me aos dois volumes de Educação Comparada. Panorama internacional e perspectiva, organizados por Robert Cowen e Andreas Kazamias (com a colaboração de Elaine Unterhalter). E, penso que posso acrescentar um próximo, organizado por Robert F. Arnove, Carlos Alberto Torres e Stephen Franz, Comparative Education. The Dialetic of the Global and the Local, do qual participo com a autoria do capítulo sobre a construção política da educação na Europa (ARNOVE; TORRES; FRANZ, 2012).

No volume 2 de Educação Comparada, organizado por Cowen e Kazamias (com Unterhalter), figuram dois interessantes capítulos de natureza prospectiva. Um, de Patricia Broadfoot, uma influente e conhecida comparatista britânica, e outro, de Robert Cowen, um dos organizadores da coletânea e igualmente conhecido e influente comparatista.

Patricia Broadfoot, no seu capítulo Tempos de revolução cientifica? Da Educação Comparada à Ciência Comparada de Aprendizagem (p. 717-738, da edição brasileira, 2012), apresenta uma impiedosa crítica ao modelo dominante de Educação Comparada assente nos grandes inquéritos estatísticos padronizados, internacionais (e nacionais). Diz 
mesmo que "esse projeto baseia-se em um modelo de educação que assume o formato tamanho único", o que,

[...] ]evidentemente, trata-se de um modelo imperfeito, não só por não levar em consideração diferenças contextuais importantes entre os países envolvidos, mas também por não questionar as estruturas e o provimento aceitos da educação formal, tal como essa educação evoluiu ao longo do último século (p. 724).

\section{E acrescenta:}

Quanto mais os países se esforçam por fazer comparações entre si por meio desses critérios comuns, mais improvável se torna a busca por outros tipos de resultados de aprendizagem menos susceptiveis de avaliação formal, ainda que possam ser mais importantes (p. 724).

Em outro capítulo, intitulado Antes e agora: ideias-unidade e Educação Comparada, Robert Cowen (2012) defende que há várias educações comparadas:

Por exemplo, ainda temos uma educação comparada de soluções oferecidas por agências como a OCDE ou o Banco Mundial; uma educação comparada de avaliações internacionais - os estudos IEA e Pisa, e o movimento eficiente e eficaz das escolas, que ainda está vivo; uma educação comparada das dicotomias politicamente santificadas ou politicamente corretas (tradicional/moderno; desenvolvido/em desenvolvimento; capitalista/socialista; Oriente/Ocidente; Norte/Sul); e uma literatura de educação superior comparada especializada e de boa qualidade (p. 759).

Estas diferentes "educações comparadas" produzem discursos paralelos que raramente se encontram e se cruzam. O Brasil não é exceção. Por exemplo, o Inep produz uma abundante literatura a partir do PISA e das muitas provas estandardizadas que realiza, que é (quase) totalmente ignorada pela comunidade das Ciências da Educação (e das Ciências Sociais). Também, simetricamente, a produção científica saída da comunidade universitária, das centenas de programas de doutoramento e mestrado, pouco ou nenhum reconhecimento têm na ocasião da formulação de políticas públicas. São dois mundos que, majestaticamente, se ignoram. 
É neste contexto que termino com uma proposta. A Capes é uma tecno-estrutura de natureza governamental com forte participação da comunidade científica, estando por isso em excelentes condições para liderar o passo seguinte a este que tem dado ultimamente (o de possibilitar o acesso a importantes obras da Educação Comparada "mundial"): permitir que esses discursos paralelos, essas "duas culturas", se cruzem e dialoguem. E, ao se cruzarem e dialogarem, criar condições para uma Educação Comparada, ou uma Ciência Comparada da Aprendizagem, como defende Broadfoot (2012), que esteja atenta à inovação, à experimentação, a novas "gramáticas" da organização da escola e da universidade, à capacidade de construir nas políticas (e práticas) de educação pública aquilo que Paulo Freire designou de inéditos viáveis. $\mathrm{E}$ a educação e as sociedades bem precisam desse esforço: a escola está a tornar-se algo "baita chato" para milhões de crianças e jovens, mesmo entre aquelas que vêm de camadas próximas da cultura escolar. E também importa nunca esquecer que os grandes crimes da humanidade, onde o terrorismo indiscriminado se faz em nome de um deus, ou mesmo os atos de intolerância que afloram na sociedade brasileira, são realizados por jovens (e menos jovens) muito escolarizados, alguns deles provenientes das melhores universidades e das camadas sociais com melhores condições de vida. 


\section{Notas explicativas}

A maior das quais é, seguramente, protagonizada pela Revolução Francesa de 1789. Sobre as suas consequências no plano ideológico, com a emergência do liberalismo enquanto o cimento ideológico da economia mundo capitalista, e com a afirmação, no plano do poder, do povo que se torna soberano (ver, por exemplo,Wallerstein, 1995, p. 93-107).

i Os estudos comparativos em vários campos científicos, particularmente no seio das Ciências Biológicas, mas também no campo do Direito, da Linguística ou da Pedagogia, tiveram, no início do século XIX, um forte impulso. Na Pedagogia, deve-se a Marc-Antoine Julien de Paris, e ao seu Esquisse et vues préliminaires d'un ouvrage sur l'éducation comparée, publicado em Paris em 1817, o impulso fundador do que veio a constituir o campo da Educação Comparada. Há uma edição portuguesa desta obra, preparada pelo professor Joaquim Ferreira Gomes: Esboço de uma obra sobre a Pedagogia Comparada (2 ed. Lisboa: Instituto de Inovação Educacional, 1998).

iii Tive a oportunidade de confirmar essa afirmação com Maria do Carmo Clímaco, que representou Portugal nas reuniões que prepararam o lançamento do projeto, bem como com Ana Benavente, que, no final dos anos 1990 e início de 2000, representou Portugal no Comité Diretivo da OCDE (cf. memorandum da oficina de trabalho "Organizações internacionais e regulação transnacional das políticas educativas: os indicadores de comparação internacional e a construção de uma agenda global de educação", realizada em 22 de março de 2007, em Lisboa, no âmbito da Rede Iberoamericana de Investigação em Políticas de Educação - RIAIPE).

iv De uma forma mais detalhada, ver a génese deste projeto em $A$ regulação transnacional das políticas educativas. O papel dos indicadores de comparação internacional na construção de uma agenda global de educação, comunicação apresentada por Madalena Mendes e Carla Galego na 8th Conference of European Sociological Association, que teve lugar na Escócia, de 3 a 6 de setembro de 2007. Este trabalho foi realizado no âmbito da Rede Iberoamericana de Políticas de Educação e do Projecto Educating the Global Citizen, financiado pela Fundação para a Ciência e a Tecnologia (Ref ${ }^{a}$ POCl/ CED/56992/2004 e PPCDT/CED/56992/2004).

$\checkmark$ Esclarece-se de novo que esta afirmação se reporta aos países centrais ou na semiperiferia dos espaços centrais, bem como aos chamados países emergentes, que atualmente integram ou são membros associados da 
OCDE. Para os países do chamado Terceiro Mundo, na periferia do sistema mundial, outras são as relações de força que se estabelecem, por exemplo entre instituições financeiras como o Banco Mundial ou o FMl e os governos nacionais.

vi "A regra do reconhecimento permite, essencialmente, a apropriação de realizações para serem colocadas em conjunto. A regra da realização determina como colocamos significados em conjunto e os tornamos públicos. A regra da realização é necessária para produzir o texto legitimado. Assim, diferentes valores de enquadramento atuam seletivamente nas regras de realização e na produção de diferentes textos. De modo simples, as regras de reconhecimento regulam os significados que são relevantes e as regras de realização como os significados são colocados em conjunto para criar o texto legitimado" (BASIL BERNSTEIN, citado por Dale, 2008, p. 3).

vii Esta minha posição, defendida desde a publicação do artigo Organizações internacionais e políticas educativas nacionais: a emergência de novas formas de regulação transnacional ou uma globalização de baixa intensidade, em 2001, é corroborada por Henry, Lingard, Rizvi e Taylor (2001).

viii Third/Trends in Internationa/Mathematics and Science Study. Publicado em 1995, com a designação de Third, passou, a partir de 1999, a designar-se de Trends. Conduzidos pela International Association for the Evaluation of the Educational Achievement (IEA), foram realizadas até agora as edições de 1995, 1999, 2003, 2007, 2011 e 2015. Em http:/ /timssandpirls.bc.edu podese obter a informação relevante sobre este survey.

ix Program for International Student Assessment. Este estudo foi lançado pela OCDE em 1997 e teve, até agora, três ciclos. O primeiro, que decorreu em 2000, teve como principal domínio de avaliação a literacia em contexto de leitura e envolveu cerca de 265.000 alunos de 15 anos, de 32 países. No segundo ciclo, realizado em 2003, participaram 41 países, envolvendo mais de 250.000 alunos de 15 anos, dando uma maior ênfase à literacia matemática e tendo como domínios secundários as literacias de leitura e científica, bem como a resolução de problemas. No terceiro ciclo, que decorreu em 2006, houve preponderância da literacia científica e contou com a participação de cerca de 60 países, envolvendo mais de 200.000 alunos de 7.000 escolas. Uma nova edição foi realizada em 2011 e está prevista outra para 2016. 0 site oficial do PISA encontra-se em http://www.oecd.org/pisa/home/. 
x Progress in International Reading Literacy Study. Este projecto, conduzido pela International Association for the Evaluation of the Educational Achievement (IEA), realizou dois ciclos de recolha de dados. Do primeiro, denominado PIRLS 2001, participaram cerca de 150.000 alunos do $4^{\circ}$ ano de escolaridade em 35 países. Do segundo, PIRLS 2006, já participaram crianças do $4^{\circ}$ ano de 45 sistemas escolares, abrangendo um mínimo de 150 escolas, com um total de 4.500 a 5.000 alunos a serem testados em cada um dos sistemas escolares participantes. Em http://timssandpirls. bc.edu pode-se obter a informação relevante sobre este survey.

xi Teaching and Learning International Survey. Em setembro de 2007 tinham participado 24 países. Este projeto é apresentado como o primeiro survey international, onde o foco principal situa-se no contexto de aprendizagem e nas condições de trabalho dos professores nas escolas. Em 2013 realizouse um novo survey. Os seus resultados podem ser consultados em http:/ / www.oecd.org/edu/school/talis.htm.

xii Mesmo que, muitas vezes, os seus mentores não tenham condições para explicitar este ponto de vista, a política baseada em evidências tem, contudo, consequências claras: operar, simultaneamente, como legitimação das políticas adoptadas e desqualificação de políticas alternativas, apontadas como resultado de interesses particulares que não têm suporte técnicocientífico nem respondem ao interesse geral.

\section{Referências}

AFONSO, A.; ST. AUBYN, M. Cross-country efficiency of secondary education provision: A semi-parametric analysis with non-discretionary inputs. Economic Modelling, v. 23, p. 476-491, 2006.

ARNOVE, R. F., TORRES, C. A.; FRANZ, S. (Eds.). Comparative Education. The dialect the global and the local. 4. ed. New York: Roman \& Littlefield, 2012.

BARROSO, J. Os Liceus. Organização pedagógica e administração (1836-1960). Lisboa: Fundação Calouste Gulbenkian / Junta Nacional de Investigação Científica e Tecnológica, 1995. 2 v. 
BAUTIER, E. et al. Performances en littéracie, modes de faire et univers mobilisés par les élèves: analyses secondaires de l'enquête PISA 2000. Révue Française de Pédagogie, n. 157, p. 85-101, 2006.

BOTTANI, N. Usages et mésusages des approches comparatives dans un cadre politique. In: SIROTA, R. (Ed.). Autour du Comparatisme en Education. Paris: PUF, 2001. p. 71-76.

BOTTANI, N.; WALBERG, H. J. À quoi servent les indicateurs internationaux de l'enseignement? In: CERI. L'OCDE et les indicateurs internacionaux de l'enseignement. Un cadre d'analyse. Paris: OECD/OCDE, 1992. p. 7-13.

BROADFOOT, P. Tempos de revolução científica? Da educação comparada à ciência comparada da aprendizagem. In: COWEN, R.; KAZAMIAS, A. M.; UNTERHALTER, E. Educação Comparada. Panorama internacional e perspectivas. Brasília: UNESCO Brasil / Fundação Capes, 2012. v. 2, p. 717-738.

BROADFOOT, P. et al. Promoting Quality in Learning: Does England Have the Answer? London: Cassell, 2000.

CARNOY, M. International Test Score Comparisons and Educational Policy: a Review of the Critics. Palo Alto: National Education Policy Center, Standford University, 2015. Disponivel em: <http://nepc.colorado.edu/ publication/international-test-scores>. Acesso em: 17 abr. 2016.

COWEN, R. Antes e agora: ideias-unidade e educação comparada. In: COWEN, R.; KAZAMIAS, A. M.; UNTERHALTER, E. Educação Comparada. Panorama internacional e perspectivas. Brasília: UNESCO Brasil / Fundação Capes, 2012. v. 2, p. 749-770.

DALE, R. Brief Critical Commentary on CWEC and GSAE 8 Years on. Paper presented to 52th Confererence Comparative and International Education Society (CIES), Teachers College, Columbia University, New York, March 2008. p. 17-21.

GREEN, A. Education, globalisation and the role of comparative research. London: Institute of Education/University of London, 2002. 
HENRY, M. et al. The OECD, Globalisation and Education Policy. Amesterdam: Pergamon \& Elsevier Science, 2001.

Husén, T. L'école en question. Bruxelas: Pierre Mardaga,1979.

MAGALHÃES, J. Ler e escrever no mundo rural do Antigo Regime: um contributo para a história da alfabetização e da escolarização em Portugal. Braga: Instituto de Educação da Universidade do Minho, 1994.

MEYER, J. W.; RAMIREZ, F. O. The World Institutionalization of Education. In: SCHRIEWER, J. (Ed.). Discourse Formation in Comparative Education. Frankfurt: Peter Lang, 2000. p. 111-132.

NORMAND, R. Les comparaisons internationales de résultats: problèmes épistemologiques et questions de justice. Éducation et Sociétés, n. 12, p. 73-89, 2003.

. La formation tout au long de la vie et son double. Contribution à une critique de l'économie politique de l'efficacité dans l'éducation. Éducation et Sociétés, n. 13, p. 103-118, 2004.

NÓVOA, A. História da Educação. Provas de agregação não publicadas. Lisboa: Faculdade de Psicologia e Ciências da Educação da Universidade de Lisboa, 1994.

Histoire \& Comparaison: Essais sur l'Éducation. Lisboa: Educa,1998.

Vers un Comparatisme Critique. Regards sur l'éducation. Colaboração de T. Yariv-Mashal. Cadernos Prestige, Lisboa: Educa, n. 24, 2005.

PETITAT, A. Production de l'école, production de la société: analyse socio-historique de quelques moments décisifs de l'évolution scolaire en Occident. Genebra: Librairie Droz, 1982.

POPKEWITZ, T. S.; PEREYRA, M. A. Estudio comparado de las prácticas contemporáneas de reforma de la formación del profesorado en 
ocho países: configuración de la problemática y construcción de una metodología comparativa. In: POPKEWITZ, T. S. (Comp.). Modelos de poder y regulación social en Pedagogia. Crítica comparada de las reformas contemporáneas de la formación del profesorado Barcelona: Ediciones Pomares-Corredor,1994.

SAMOFF, J. Institutionalizing International Influence. In: ARNOVE, R. A.; TORRES, C. A. (Eds.). Comparative Education: the Dialectic of the Global and the Local. 3. Ed. Lanham: Rowman \& Littlefield, 2007. p. 47-77.

SCHRIEWER, J. L'éducation comparée: mise en perspective historique d'un champ de recherche. Révue Française de Pédagogie, n.121, p. 9-27, 1997.

SIROTA, R., Introduction. Autour du comparatisme. In: R. SIROTA, R. (Dir.). Autour du comparatisme en éducation. Paris: PUF, 2001. p. 1-18.

TEODORO, A. Organizações internacionais e políticas educativas nacionais: a emergência de novas formas de regulação transnacional ou uma globalização de baixa intensidade. In: STOER, S. R.; CORTESÃO, L.; CORREIA, J. A. (Orgs.). Da crise da educação à "educação" da crise: educação e a transnacionalização dos mecanismos de regulação social. Porto: Edições Afrontamento, 2001. p. 125-161.

Educational Policies and New Ways of Governance in a Transnationazation Period. In:TORRES, C. A.; ANTIKAINEN, A. (Eds.). The International Handbook on the Sociology of Education: an International Assessment of New Research and Theory. Lanham, MA: Rowman \& Littlefield, 2003a. P. 183-210.

Globalização e Educação. Políticas educacionais e novos modos de governação. Porto: Edições Afrontamento [Ed. Portuguesa], 2003b.

Nouvelles modalités de régulation transnationale des politiques éducatives. Évidences et possibilités. Carrefours de l'éducation, n. 24, p. 201-215, 2007.

A educação em tempos de globalização neoliberal. Os novos modos de regulação transnacional. Brasília: Liber Livro, 2011. 
TYACK, D.; CUBAN, L. Tinkering toward Utopia: a Century of Public School

Reform. Cambridge, Massachusetts: Harvard University Press, 1995.

WALLERSTEIN, I. After Liberalism. New York: The New Press, 1995. 